04.1

\title{
Электроотрицательные добавки как способ повышения эффективности использования тока разряда при конверсии летучих органических соединений
}

\author{
() Д.Л. Кузнецов ${ }^{1,2}$, И.Е. Филатов ${ }^{1}$, В.В. Уварин ${ }^{1}$ \\ ${ }^{1}$ Институт электрофизики УрО РАН, Екатеринбург, Россия \\ ${ }^{2}$ Уральский фредеральный университет им. Б.Н. Ельцина, Екатеринбург, Россия \\ E-mail: kdl@iep.uran.ru
}

Поступило в Редакцию 11 июня 2019г.

В окончательной редакции 28 октября 2019 г.

Принято к публикации 29 октября 2019г.

Исследовано влияние электроотрицательных добавок на процессы конверсии токсичных примесей в плазме воздушных смесей. На примере конверсии трихлорэтилена $\left(\mathrm{C}_{2} \mathrm{HCl}_{3}\right)$ в воздухе под действием импульсного коронного разряда наносекундной длительности показано, что добавление в смесь тетрахлорметана $\left(\mathrm{CCl}_{4}\right)$ приводит не только к снижению тока разряда, но и к повышению энергетической эффективности конверсии. Проведен анализ процессов в различных областях коронного разряда.

Ключевые слова: импульсный коронный разряд, конверсия, электроотрицательные добавки, прилипание электронов.

DOI: 10.21883/PJTF.2020.03.48984.17923

Процессы прилипания электронов к электроотрицательным молекулам воздушных смесей оказывают существенное влияние на свойства плазмы и на процессы, протекающие в ней. Электроотрицательными компонентами таких смесей являются кислород и некоторые токсичные примеси $\left(\mathrm{SO}_{2}, \mathrm{CS}_{2}\right.$ и др.). Процессы прилипания снижают концентрацию плазменных электронов, что приводит к снижению разрядного тока. Отрицательные ионы могут участвовать в процессах конверсии токсичной примеси, как в случае удаления диоксида серы [1], а могут не участвовать в конверсии, как в случае разложения сероуглерода [2]. Известно, что процессы прилипания к молекулам одного типа могут приводить к образованию различных отрицательных ионов [3]. Добавление в газовые смеси хлор- и фторсодержащих молекул с наибольшими значениями энергии сродства к электрону приводит к заметным изменениям свойств разрядов и плазмы $[4,5]$.

Анализ результатов экспериментов по конверсии непредельных летучих органических соединений (ЛОС) в разрядной плазме показывает, что конверсия инициируется электронами с энергиями, достаточными для активации двойных химических связей. Поэтому степень конверсии соединения должна находиться в прямой зависимости от количества электронов в плазме. При добавлении в смесь электроотрицательного вещества можно ожидать, что в разрядной плазме снизится концентрация электронов, а это приведет к снижению тока разряда и одновременно к пропорциональному снижению степени конверсии непредельного ЛОС, т. е. кривая в координатах концентрация ЛОС-количество разрядных импульсов для смеси с добавкой должна иметь меньший наклон, а кривая в координатах концентрация ЛОС-удельный энерговклад должна остаться практически неиз- менной. Иными словами, электроотрицательные добавки не должны приводить к изменению энергетической эффективности конверсии непредельных ЛОС. Однако эксперименты по конверсии ЛОС в плазме импульсного коронного разряда не подтверждают приведенные выше выводы. Так, при конверсии перхлорэтилена $\left(\mathrm{C}_{2} \mathrm{Cl}_{4}\right)$ электроотрицательные добавки приводят к повышению энергетической эффективности конверсии [6]. Для объяснения противоречия необходимы дополнительные эксперименты по конверсии другого непредельного ЛОС. В качестве токсичного компонента был выбран трихлорэтилен $\left(\mathrm{C}_{2} \mathrm{HCl}_{3}\right)$, а в качестве электроотрицательной добавки - тетрахлорметан $\left(\mathrm{CCl}_{4}\right)$. Задача настоящей работы заключается в исследовании влияния добавки $\mathrm{CCl}_{4}$ на конверсию $\mathrm{C}_{2} \mathrm{HCl}_{3}$ в плазме импульсного коронного разряда и объяснении полученных результатов.

Для проведения экспериментов использовалась установка, устройство которой описано в $[2,6]$. Импульсный коронный разряд зажигался между стальным цилиндром (диаметр $88 \mathrm{~mm}$, длина $56 \mathrm{~cm}$ ) и стальной проволокой диаметром $0.24 \mathrm{~mm}$, расположенной на оси цилиндра. Проволока играла роль высоковольтного катода, а цилиндр - заземленного анода. Разряд формировался в воздушных смесях атмосферного давления, содержавших примесь $\mathrm{C}_{2} \mathrm{HCl}_{3}$. Осциллограммы напряжения, тока разряда и энерговклада в смесь без добавки и с добавкой $\mathrm{CCl}_{4}$ приведены на рис. 1. Форма импульса тока объясняется наличием в нем двух составляющих: собственно тока разряда и тока затухающих колебаний в $L C$-контуре, образованном конструктивной индуктивностью и емкостью разрядной камеры. В обеих смесях происходят процессы прилипания электронов к трихлорэтилену, что приводит к снижению тока разряда и энерговклада на $\sim 20 \%$ по сравнению с разрядом в 


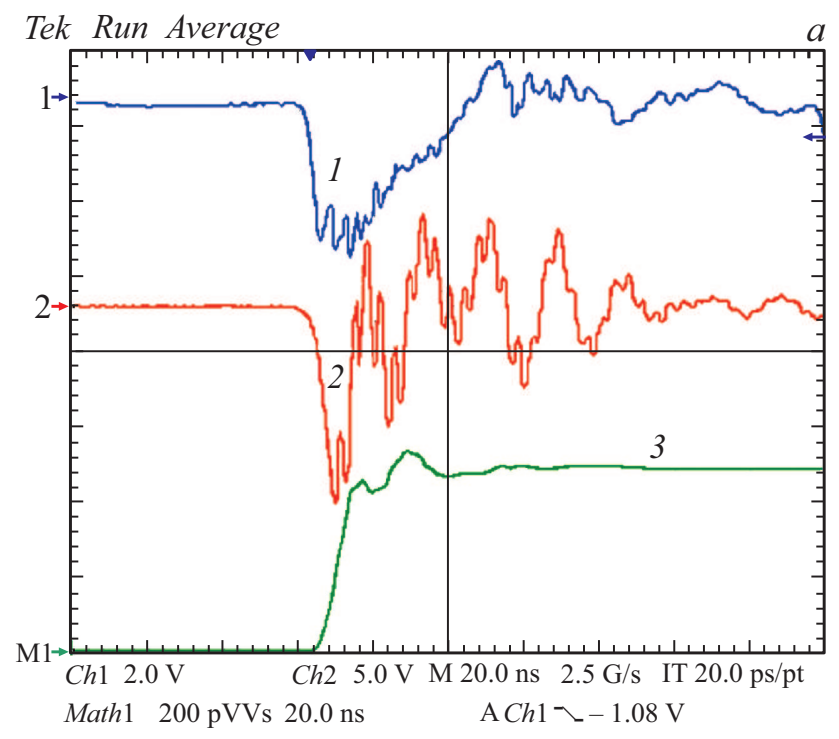

Tek Run Average

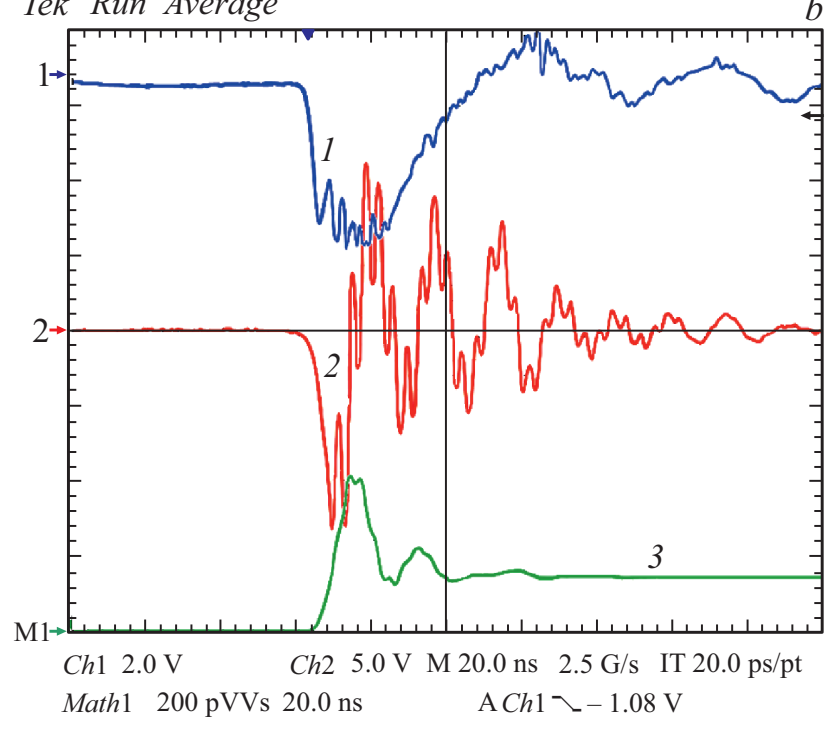

Рис. 1. Осциллограммы напряжения (1), тока в разрядном промежутке (2) и энерговклада в газовую смесь (3) за один импульс разряда в воздухе атмосферного давления с примесью $1000 \mathrm{ppm} \mathrm{C}_{2} \mathrm{HCl}_{3}(a)$ и с дополнительной добавкой $5000 \mathrm{ppm}$ $\mathrm{CCl}_{4}(b)$. Масштаб по вертикали - 75kV/cell (1), $270 \mathrm{~A} /$ cell (2), $0.2 \mathrm{~J} /$ cell (3); по горизонтали - $20 \mathrm{~ns} /$ cell.

чистом воздухе. Добавление $\mathrm{CCl}_{4}$ существенно изменяет параметры разряда. Осциллограмма тока становится более симметричной относительно горизонтальной оси, что свидетельствует о существенном уменьшении собственно разрядной компоненты тока. Как следствие, наблюдается снижение энерговклада более чем в 3 раза (с 0.5 до $0.15 \mathrm{~J}$ ).

Результаты экспериментов по конверсии $\mathrm{C}_{2} \mathrm{HCl}_{3}$ представлены на рис. 2. Видно, что добавки $\mathrm{CCl}_{4}$ приводят к более резкому снижению концентрации $\mathrm{C}_{2} \mathrm{HCl}_{3}$, т.е. помимо снижения энерговклада наблюдается повышение энергетической эффективности конверсии. При построении этих зависимостей в координа- тах концентрация-число разрядных импульсов выяснилось, что добавление $\mathrm{CCl}_{4}$ не только не снижает степень конверсии трихлорэтилена, но и приводит к некоторому (около 10\%) ее повышению. Таким образом, как и в случае конверсии перхлорэтилена, энергетическая эффективность конверсии увеличивается.

На рис. 3, $a$ показаны области импульсного коронного разряда в конфигурации проволока-цилиндр. Напряженность электрического поля $E(r)$ в промежутке равна

$$
E(r)=\left[U / \ln \left(R_{2} / R_{1}\right)\right][1 / r],
$$

где $U-$ напряжение между катодом и анодом, $R_{1}$ - радиус проволоки, $R_{2}-$ радиус цилиндра, $r-$ расстояние от оси цилиндра. Это позволяет выделить в разрядном промежутке три области: I - область сильного поля $(r<5 \mathrm{~mm}, E>50 \mathrm{kV} / \mathrm{cm})$; II - область умеренного поля $(5<r<20 \mathrm{~mm}$, $12.5<E<50 \mathrm{kV} / \mathrm{cm}) ;$ III - область слабого поля $(20<r<44 \mathrm{~mm}, 5.8<E<12.5 \mathrm{kV} / \mathrm{cm})$. На рис. $3, b$ показана зависимость приведенной напряженности электрического поля $E / n(n-$ концентрация газа) от расстояния $r$ (кривая 3). Известно, что параметр $E / n$ определяет температуру электронов. Оценку температуры электронов можно выполнить по эмпирическим формулам (см., например, [7]), путем оптических измерений [8] и т.д., причем полученные оценки могут существенно различаться. Нами использованы оценки, выполненные авторами работы [9] для отрицательной короны в воздухе при конфигурации электродов провод-цилиндр. На основе этих оценок построена зависимость температуры электронов $T_{e}$ от расстояния $r$ (рис. $3, b$, кривая 4 ). Видно, что в области сильного поля $T_{e} \geqslant 6 \mathrm{eV}$, в области умеренного - $1 \leqslant T_{e}<6 \mathrm{eV}$, в области слабого $T_{e}<1 \mathrm{eV}$.

Сначала рассмотрим процессы в газе без электроотрицательных компонентов, например в чистом азоте.

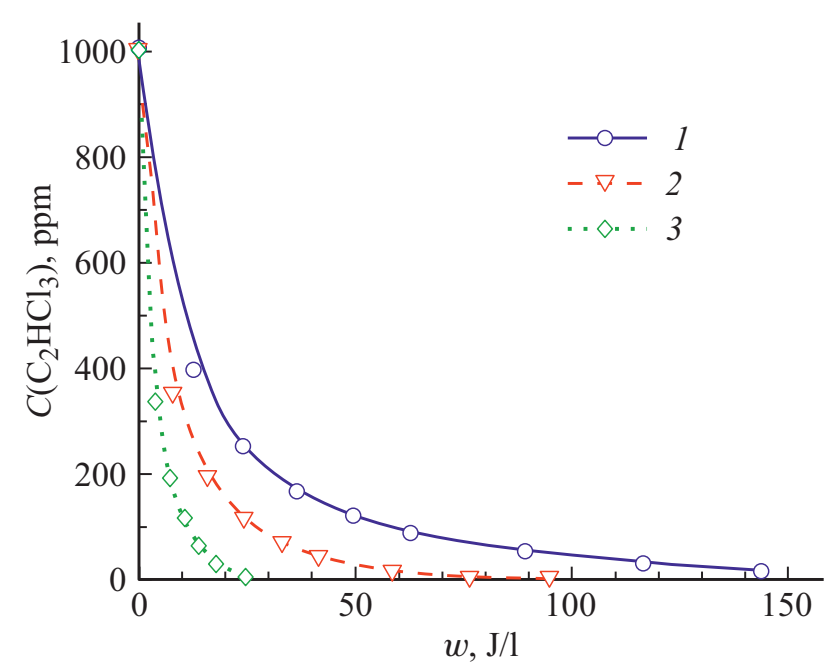

Рис. 2. Зависимости концентрации трихлорэтилена $C\left(\mathrm{C}_{2} \mathrm{HCl}_{3}\right)$ от удельного энерговклада $w$ в газовую смесь. 1 - начальный состав смеси $1000 \mathrm{ppm} \mathrm{C}_{2} \mathrm{HCl}_{3}$ в воздухе атмосферного давления, 2 и $3-$ с добавлением 1000 и $5000 \mathrm{ppm} \mathrm{CCl}_{4}$ соответственно. 


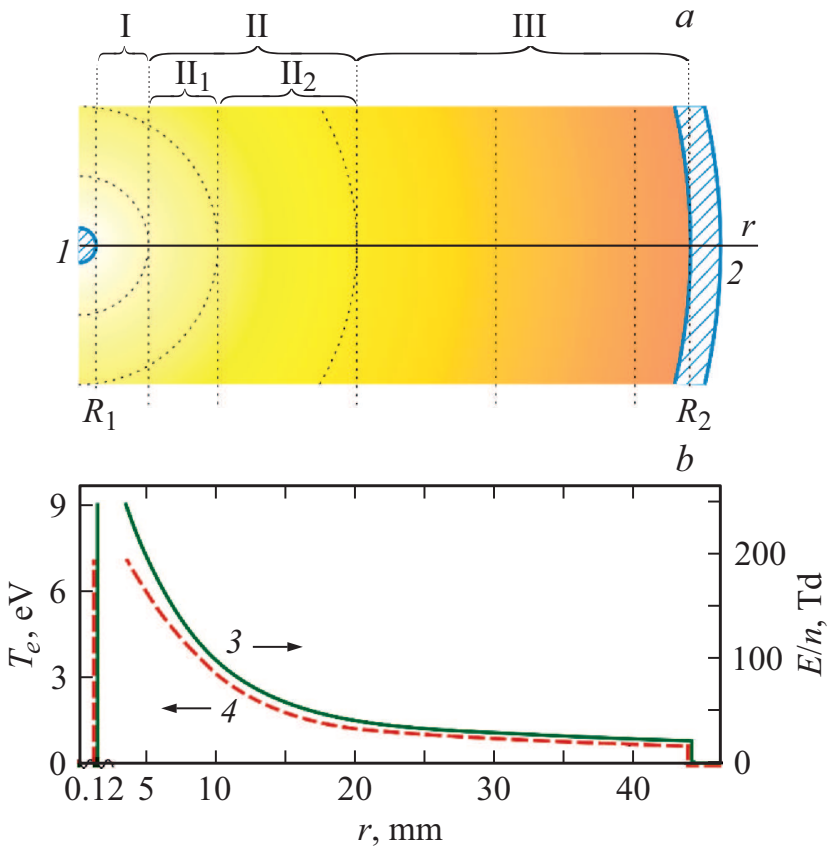

Рис. 3. $a-$ области импульсного коронного разряда, формируемого между проволочным катодом (1) и цилиндрическим анодом (2); $b-$ зависимости приведенной напряженности электрического поля $E / n(3)$ и температуры электронов $T_{e}(4)$ от расстояния $r$ от оси цилиндра.

Поскольку сечение ионизации электронами максимально при энергии электронов $\sim 100 \mathrm{eV}$ [10], процессы ударной ионизации возможны только в области сильного поля. Кроме того, электроны в области I способны производить диссоциацию и электронное возбуждение молекул. В области II температура электронов позволяет им участвовать лишь в двух основных процессах электронном и колебательном возбуждении молекул, причем эту область можно разделить на две подобласти: $\mathrm{II}_{1}$, в которой возможны оба процесса, и $\mathrm{II}_{2}$, в которой осуществляется лишь колебательное возбуждение молекул. В области III преобладают упругие столкновения с молекулами и дрейф электронов к аноду.

Электроотрицательные компоненты, например кислород в воздухе, изменяют ситуацию везде, кроме области I. В этой области сечение прилипания электронов минимально и прилипание практически отсутствует. Происходит ударная ионизация, диссоциация и электронное возбуждение азота и кислорода. В области $\mathrm{II}_{1}$ к перечисленным выше процессам добавляется диссоциативное прилипание, а в областях $\mathrm{II}_{2}$ и $\mathrm{III}-$ трехчастичное прилипание электронов к кислороду.

Поскольку практически все электроны рождаются в области I, а процессы прилипания здесь не происходят, средняя концентрация электронов в этой области не зависит от наличия электроотрицательных компонентов и может быть оценена по осциллограммам тока в чистом азоте как $n_{e} \approx 10^{12} \mathrm{~cm}^{-3}$.

Процессы прилипания электронов к тетрахлорметану имеют ряд особенностей. Во-первых, прилипание элек- трона к $\mathrm{CCl}_{4}$ приводит к диссоциации молекулы. Так, при малых значениях $T_{e}$ формируются ионы $\mathrm{Cl}^{-}, \mathrm{Cl}_{2}^{-}, \mathrm{CCl}_{2}^{-}$, $\mathrm{CCl}_{3}^{-}$, а при $T_{e}>3-6 \mathrm{eV}$ эффективность прилипания резко снижается [5]. Во-вторых, характерные времена прилипания электронов к $\mathrm{CCl}_{4}-$ единицы наносекунд, т.е. в течение действия импульса разряда прилипание успевает произойти в полном объеме. В-третьих, молекула $\mathrm{CCl}_{4}$ имеет высокую константу скорости прилипания: $k_{a}\left(\mathrm{CCl}_{4}\right)=2.4 \cdot 10^{-7} \mathrm{~cm}^{3} / \mathrm{s}$. На основе этого можно сделать следующие оценки. При зажигании разряда в смеси воздуха с 1000 ppm $\mathrm{C}_{2} \mathrm{HCl}_{3} \sim 27 \%$ электронов плазмы прилипает к молекулам трихлорэтилена, причем процессы прилипания происходят только в областях умеренного и слабого поля, а средняя концентрация отрицательных ионов составляет $n_{-} \approx 3.7 \cdot 10^{9} \mathrm{~cm}^{-3}$. При добавлении в смесь $5000 \mathrm{ppm} \mathrm{CCl}_{4} \sim 79 \%$ электронов прилипает к электроотрицательным молекулам $(27 \%$ к $\mathrm{C}_{2} \mathrm{HCl}_{3}, 52 \%$ к $\left.\mathrm{CCl}_{4}\right)$, при этом процессы прилипания также происходят только в областях II и III, а средняя концентрация всех отрицательных ионов достигает $n_{-} \approx 1.1 \cdot 10^{10} \mathrm{~cm}^{-3}$.

Итак, конверсия непредельных хлорсодержащих ЛОС инициируется только в области сильного поля, в которой не происходят процессы прилипания электронов. Прилипание электронов в областях умеренного и слабого поля снижает ток разряда и энерговклад в газовую смесь за счет снижения концентрации электронов, не участвующих в конверсии ЛОС, при этом процессы конверсии в области сильного поля не тормозятся, а энергетическая эффективность конверсии повышается.

Следует отметить, что в процессе конверсии токсичных хлорсодержащих ЛОС под действием импульсного коронного разряда могут образовываться различные токсичные соединения, в том числе фосген. Поэтому при разработке систем очистки нужно предусмотреть дополнительные стадии удаления токсичных продуктов конверсии, а также электроотрицательных добавок. Однако этот вопрос не является предметом рассмотрения в настоящей работе и будет решаться в ходе дальнейших исследований.

Таким образом, введение в смесь электроотрицательных хлорсодержащих добавок можно рассматривать как способ повышения энергетической эффективности конверсии некоторых непредельных ЛОС под действием импульсного коронного разряда. Это повышение достигается за счет пространственного разделения процессов конверсии и прилипания электронов.

\section{Финансирование работы}

Работа выполнена при финансовой поддержке Российского фонда фундаментальных исследований (проект № 17-08-01212a).

\section{Конфликт интересов}

Авторы заявляют, что у них нет конфликта интересов. 


\section{Список литературы}

[1] Novoselov Y.N., Mesyats G.A., Kuznetsov D.L. // J. Phys. D.: Appl. Phys. 2001. V. 34. N 8. P. 1248-1255.

DOI: $10.1088 / 0022-3727 / 34 / 8 / 316$

[2] Kuznetsov D.L., Filatov I.E., Uvarin V.V. // IEEE Trans. Plasma Sci. 2019. V. 47. N 3. P. 1572-1582.

DOI: $10.1109 /$ TPS.2019.2898100

[3] Krishnakumar E., Nagesha K. // J. Phys. B. 1992. V. 25. N 7. P. 1645-1660. DOI: 10.1088/0953-4075/25/7/032

[4] Khvostenko O.G., Lukin V.G., Tuimedov G.M., Khatymova L.Z., Kinzyabulatov R.R., Tseplin E.E. // J. Electron. Spectr. Rel. Phenom. 2015. V. 199. P. 1-9.

DOI: 10.1016/J.ELSPEC.2014.12.010

[5] Braun M., Marienfeld S., Ruf M.W., Hotop H. // J. Phys. B. 2009. V. 42. N 12. P. 125202.

DOI: $10.1088 / 0953-4075 / 42 / 12 / 125202$

[6] Филатов И.Е., Уварин В.В., Кузнецов Д.Л. // Письма в ЖТФ. 2017. Т. 43. В. 24. C. 104-110. DOI: $10.21883 /$ PJTF.2017.24.45348.16857

[7] Townsend J.S., Bailey V.A. // Phil. Mag. 1921. V. 42. P. 873891. DOI: $10.1080 / 14786442108633831$

[8] Сорокин Д.А., Ломаев М.И., Банокина Т.И., Тарасенко В.Ф. // ЖТФ. 2014. Т. 84. В. 8. С. 13-20.

[9] Chen J., Davidson J.H. // Plasma Chem. Plasma Proc. 2003. V. 23. N 1. P. 83-102. DOI: 10.1023/A:1022468803203

[10] Tian C., Vidal C.R. // J. Phys. B. 1998. V. 31. N 24. P. 53695381. DOI: $10.1088 / 0953-4075 / 31 / 24 / 018$ 